\title{
New Method of Car Body Panel External Straightening: Tools of Method
}

\author{
Andrey Gnatov and Schasyana Argun \\ Kharkov National Automobile and Highway University, Petrovskogo Street 25, Kharkov 61002, Ukraine \\ Correspondence should be addressed to Schasyana Argun; shasyana@gmail.com
}

Received 23 April 2015; Revised 29 June 2015; Accepted 1 July 2015

Academic Editor: Abdelaziz Bensrhair

Copyright (C) 2015 A. Gnatov and S. Argun. This is an open access article distributed under the Creative Commons Attribution License, which permits unrestricted use, distribution, and reproduction in any medium, provided the original work is properly cited.

\begin{abstract}
Recently repair and recovery vehicle body operations become more and more popular. A special place here is taken by equipment that provides performance of given repair operations. The most interesting things are methods for recovery of car body panels that allow the straightening without disassembling of car body panels and damaging of existing protective coating. Now, there are several technologies for repair and recovery of car body panels without their disassembly and dismantling. The most perspective is magnetic-pulse technology of external noncontact straightening. Basics of magnetic-pulse attraction, both ferromagnetic and nonferromagnetic thin-walled sheet metal, are explored. Inductor system calculation models of magnetic-pulse straightening tools are presented. Final analytical expressions for excited efforts calculation in the tools under consideration are introduced. According to the obtained analytical expressions, numerical evaluations of excited forces were executed. The volumetric epures of the attractive force radial distributions for different types of inductors were built. The practical testing of magnetic-pulse straightening with research tools is given. Using the results of the calculations we can create effective tools for an external magnetic-pulse straightening of car body panels.
\end{abstract}

\section{Introduction}

Number of cars in the world grows at a huge rate year by year. Unfortunately, quantity of road traffic accidents in which car body panels are damaged in a varying degree, but imminently, grows at the same time. Therefore, car body panels repair and restoration related operations are relevant and in increasing demand. And as statistics shows, up to $80 \%$ of the damages are small and medium. Half of them are dents not requiring replacement of the entire element and removable by straightening. Over $50 \%$ of these damages are in the areas with difficult or completely closed reverse access. As a result, car body recovery methods, which allow you to execute the so-called external straightening without the necessity of disassembly of car body elements and existing protective paint damage, are of special interest [1-3].

\section{Publications Analysis}

The implementation of magnetic-pulse technology in repair and recovery of transport vehicles body elements led to creation of a whole new direction, which can be formulated as development of repair and recovery of transport vehicles body methods, based on the energy of electromagnetic fields.

It should be noted that while working with metal by conventional mechanical methods (straightening, pressing, stamping, etc.) metal becomes thin and stretched. In such case top metal layer undergoes a deformation that leads to its structure disruption [3-5]. Magnetic-pulse straightening methods are devoid of these drawbacks because the interaction of the magnetic field with the induced current (fullthickness of processed metal) initiates a metal stretching by attraction forces that act throughout its full-thickness $[1,2,6-$ 9].

\section{Processes in Ferromagnetic Materials}

The objective of this part is to describe the concept, provide a simplified mathematical model predicting attracting electromagnetic forces for ferromagnetic materials, and illustrate this concept with experimental results supporting the major conclusions of the analytical study. 


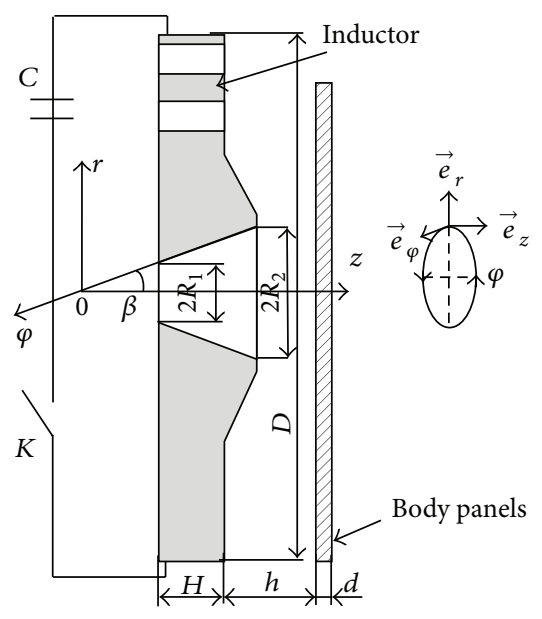

(a)

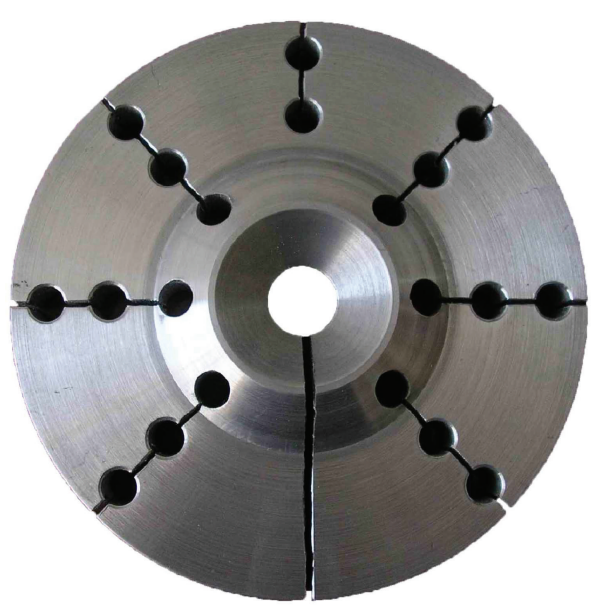

(b)

FIGURE 1: Conical induction system: (a) calculation model; (b) physical model $\left(\vec{e}_{r}, \vec{e}_{\varphi}, \vec{e}_{z}\right.$ are the unit vectors in the cylindrical coordinate system).

\section{Analytical Model of the Process and Numerical Estimates}

The inductor design in the form of flat cylindrical turn leads to the concentration of attractive forces directly under the inductor turn. This fact is caused by magnetic field strength vector module growth in radial direction from the system center with a maximum in the coil area. This issue is specified in publications $[10,11]$. The physical considerations showed that we can change the field distribution nature in the inductor system and the acting forces distribution nature, accordingly, if we configure inductor profile to frustum-of-acone shape (Figure 1). In this case, the maximum of the acting attraction forces must move to the geometric coil center. The inductor system calculation model with internal opening in frustum-of-a-cone shape is presented in Figure 1(a).

In Figure 1(b) there is the physical model of inductor system which was made of high-duty dural. Manufacturing holes and slots in the inductor need to focus the current flow on the cone facet. This will provide the necessary level of attracting effort excitement in the inductor working area. The geometrical dimensions of the inductor working area (cone facet $\left.-2 R_{2}\right)$ are $0,04 \mathrm{~m}$. The inductor outer diameter $(D)$ is $0,01 \mathrm{~m}$.

Maxwell's equations were set up according to the calculation model, displayed in Figure 1. Without dwelling on their solving let us write the final expression for the magnetic attraction force acting on the car body panel:

$$
\begin{gathered}
P_{F}(\rho, t)=-\left(1-\frac{1}{\mu_{r}}\right) \frac{\mu_{0} H_{m}^{2}}{8} \cdot \frac{i^{2}(t)}{(1-\cos (\beta))^{2}} \\
\cdot\left\{\left[\frac{\left(\operatorname{ctg}(\beta)+h / R_{2}\right)^{2}}{\left(\rho^{2}+\left(\operatorname{ctg}(\beta)+h / R_{2}\right)^{2}\right)^{2}}\right.\right.
\end{gathered}
$$

$$
\begin{aligned}
& \left.-\frac{\left(\operatorname{ctg}(\beta)+(h+d) / R_{2}\right)^{2}}{\left(\rho^{2}+\left(\operatorname{ctg}(\beta)+(h+d) / R_{2}\right)^{2}\right)^{2}}\right] \\
& +\frac{\rho}{\mu_{r}}\left[\frac{1}{\left(\rho^{2}+\left(\operatorname{ctg}(\beta)+h / R_{2}\right)^{2}\right)^{2}}\right. \\
& \left.\left.-\frac{1}{\left(\rho^{2}+\left(\operatorname{ctg}(\beta)+(h+d) / R_{2}\right)^{2}\right)^{2}}\right]\right\},
\end{aligned}
$$

where $H_{m}=L_{i} I_{m} /\left(\mu_{0} \mu_{r} \pi R_{2}^{2}\right)$ is conditional amplitude of magnetic field intensity $\mathrm{A} / \mathrm{m} ; L_{i}$ is inductivity of system, $\mathrm{H}$; $I_{m}$ is current amplitude, $\mathrm{A} ; i(t)$ is time dependence of current pulse (damped sinusoid or aperiodic signal), $\mathrm{A} ; \rho=r / R_{2}$ is relative radial coordinate.

Numerical estimates for conical induction system were carried out for the following values: $R_{1}=0,0075 \mathrm{~m}, R_{2}=$ $0,02 \mathrm{~m}, h=0,0005 \mathrm{~m}, d=0,0005 \mathrm{~m}$, slope angle of generatrix of inner cone turn $\beta=60^{\circ}, \ldots, 75^{\circ}$, and current amplitude in the inductor $50 \mathrm{kA}$. The results of calculations are presented in Figure 2.

Summing calculations results up, let us formulate main conclusions.

(1) Changing to the conical shape of the inductor inner window significantly changes the nature of the field radial distribution and the acting forces:

(i) the magnetic flux concentrates in the central zone of the inner window, unlike the flat cylindrical inductor where strength maximum occurred at the edge of the single turn inductor internal opening;

(ii) the field concentration at the system center leads to the acting forces concentration in the central area of the processed sheet. 


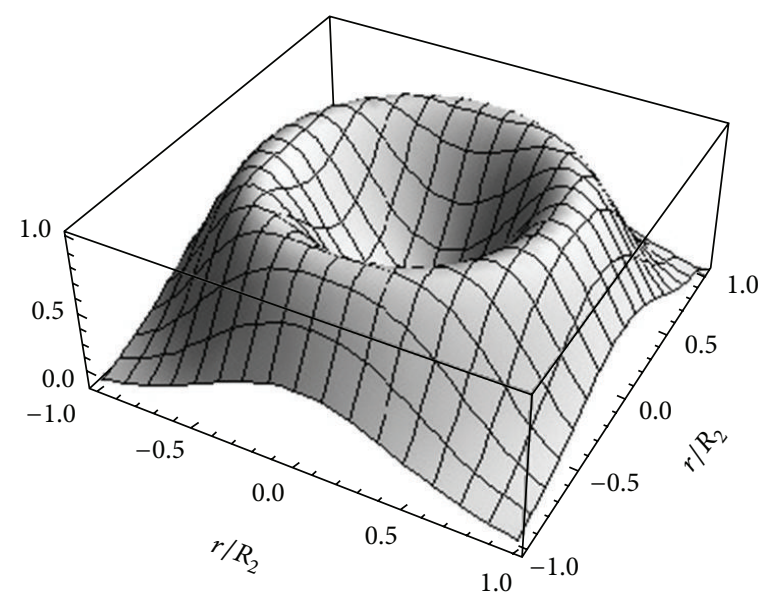

(a)

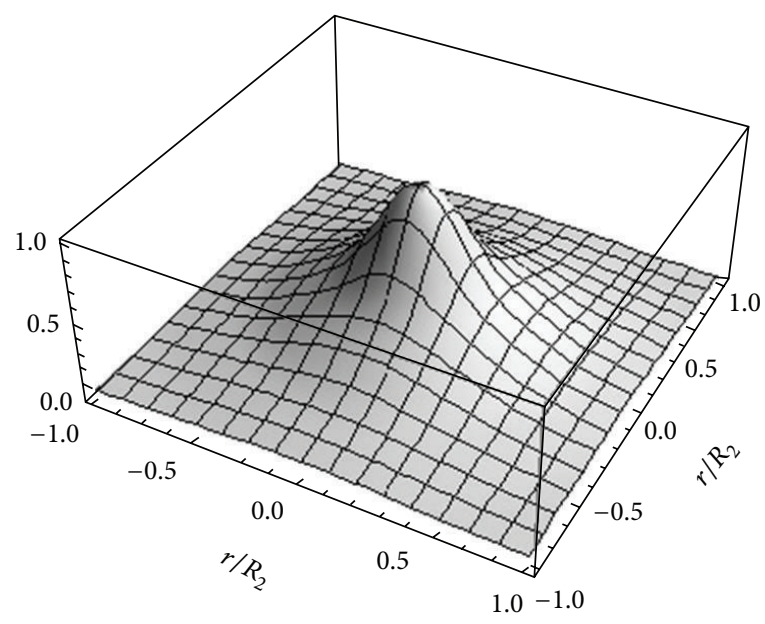

(b)

FIGURE 2: Volume epures of the attraction force radial distribution to inductor work surface: (a) with a cylindrical bore; (b) with conical bore when $\beta=60^{\circ}$.

(2) The increase of the angle of slope of the cone generator of the inner window of the inductor massive turn affects excited forces value significantly. As the angle $\beta$ is increased from $60^{\circ}$ to $75^{\circ}$ the amplitude of the attraction grows from $3 \cdot 10^{5}, \ldots, 46 \cdot 10^{5} \mathrm{~N} / \mathrm{m}^{2}$.

\section{Experimental Validation}

There is the experimental verification conducting of the proposed inductor system design. The experiments were performed on ferromagnetic modern car body panels. This practical study purpose was creating and removing of dents on car body panel. Along with that, the protective painting of car body panels must remain undamaged. The experimental setup is shown in Figure 3.

The single turn massive inductor with the working zone diameter of $40 \mathrm{~mm}$ was connected to the pulse generator via current pulse transformer with the coefficient of transformation of five. The discharge frequency was measured as $1,9 \mathrm{kHz}$. The amplitude of electric current flowing through the coil was $38 \mathrm{kA}$.

Pulsed current transformer is the matching device that complies in inductive loading of a pulse generator with a single turn inductor. It provides the necessary frequency and amplitude of the current pulse in the single turn inductor. The schematic representation (physical model) of the pulsed current transformer is presented in Figure 3(b).

The DDQ (Deep Drawing Quality) flat sheet steel samples $0,8 \mathrm{~mm}$ thick (the steel DDQ yield strength is equaled to $180 \mathrm{MPa}$, stainless steel is $350, \ldots, 300 \mathrm{MPa}$ ) were positioned next to the single turn coil. The sample was insulated from the coil with $\sim 1 \mathrm{~mm}$ layer of insulation. Initially flat samples were bulged by attraction inside the working zone of the single turn coil. The bulge was axisymmetric and had the maximum height of $1,5 \mathrm{~mm}$ at the axis of symmetry of the coil, Figure 4(a).
After the initial bulge was produced on a flat blank using the described process of electromagnetic attraction, it was flipped over, and dent removal process was physically simulated by pulling the bulge back with the electromagnetic attraction process, Figure 4(b).

The dent was successfully removed which confirmed the suggested concept.

\section{Process for Nonmagnetic Materials}

The objective of this part is to describe the concept and provide a simplified mathematical model of pulsed electromagnetic attraction of nonmagnetic materials in the "Inductor System with an Attracting Screen" as well as to illustrate the experimental results supporting the suggested concept and the major conclusions of the analytical study.

\section{Theoretical Analysis, Numerical Calculations}

The schematic of the proposed process of sheet metal attraction is employing an Inductor System with Attracting Screen (ISAS) shown in Figure 5(a).

The operating principle of this system (Figure 5) is founded on the utilization of Ampere's law, according to which conductors with collinear equally directed currents attract each other. As distinct from inductor systems which are founded on natural ferromagnetic attraction, when the existing fields operating frequency descents, ISAS is the technical solution. Here, besides the inductor (magnetic field source) and sheet billet, car body panel, we add additional structural unit. This is so-called Attracting Screen. It is arranged parallel and symmetrically to the inductor subspace and the car body panel. If the screen and car body panels are identical, instead of equal by magnitude, time dependence and direction currents are excited in them. Their interaction leads to mutual attraction. But the screen is fixedly locked. 


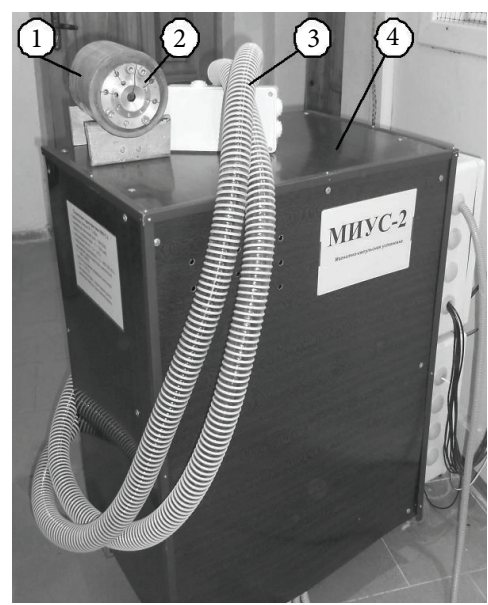

(a)

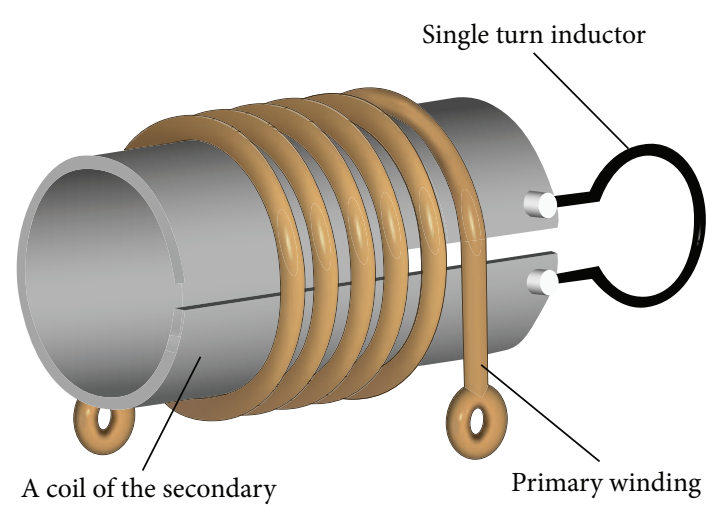

winding

(b)

FIgURE 3: The laboratory equipment for EMF attraction processes with maximum charging voltage of $2 \mathrm{kV}$ and accumulated energy of $2 \mathrm{~kJ}$ : (a) magnetic-pulse complex; (b) pulsed current transformer. (1) pulsed current transformer; (2) single turn inductor; (3) cable connection; (4) pulse generator.

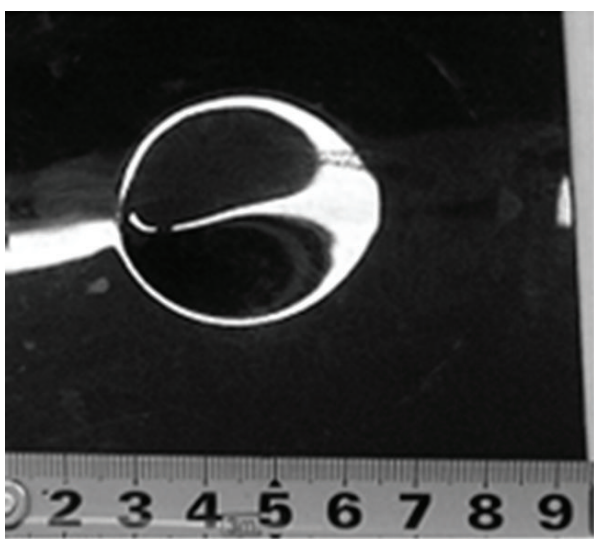

(a)

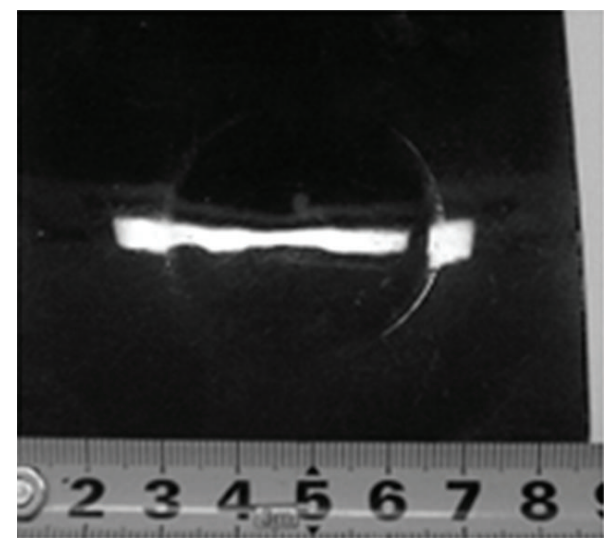

(b)

FIGURE 4: The experimental DDQ steel sample: (a) after producing the dent; (b) after removing the dent.

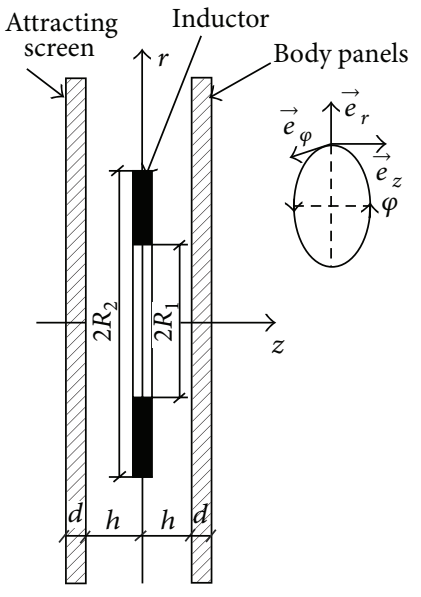

(a)

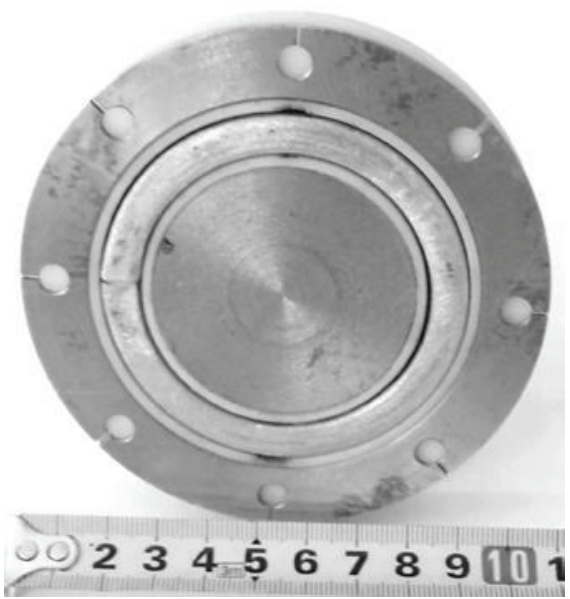

(b)

FIgURE 5: Schematic of ISAS: (a) calculation model; (b) physical model. 


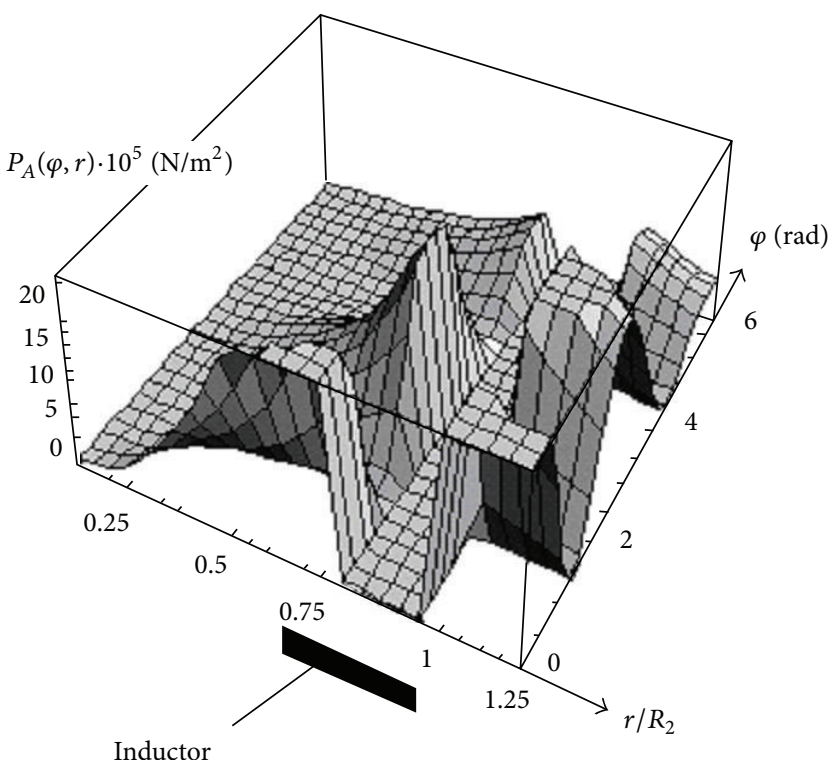

(a)

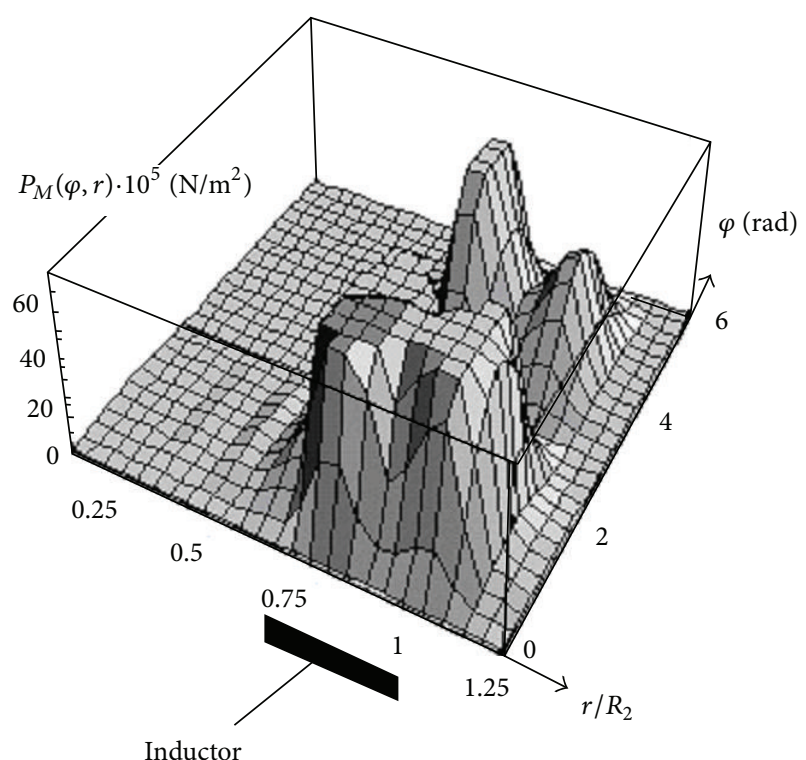

(b)

FIGURE 6: The volume epures of phase-space distribution of time highs of excited attraction forces for magnetic metals: (a) Ampere's attraction force; (b) the magnetic attraction force.

Therefore, only car body panel is flexed; its site in the internal window area will be attracted to the inductor.

Solving the composed Maxwell's equations we obtain the formulas to determine the desired quantities. We write the expression to determine the attraction force according to Ampere's law:

$$
P_{A}(\varphi, r)=P_{A m}(\varphi)\left(\int_{0}^{\infty} \Phi_{3}(x) J_{1}\left(x \frac{r}{d}\right) d x\right)^{2}
$$

where

$$
\begin{aligned}
& \Phi_{3}(x) \\
& =\frac{F(x) \cdot\left((1-\operatorname{ch}(x))-\left(1 / \mu_{r}\right) \operatorname{sh}(x)\right)}{x^{3}\left(\operatorname{sh}(x)\left[\operatorname{sh}(x h / d)+\left(1 / \mu_{r}^{2}\right) \operatorname{ch}(x h / d)\right]+\left(1 / \mu_{r}\right) e^{x h / d} \operatorname{ch}(x)\right)}
\end{aligned}
$$

$F(x)=\int_{\left(x \cdot R_{1} / d\right)}^{\left(x \cdot R_{2} / d\right)} y \cdot J_{1}(y) d y$ is the function of the current radial distribution in the inductor in terms of variable $y=(\lambda \cdot r)$; $\lambda$ is the Fourier-Bessel's transformation parameter; $J_{1}(y)$ is Bessel's function of the first kind;

$$
P_{A m}(\varphi)=\frac{\mu_{0}}{2} \cdot \frac{r}{h}\left(I_{m} \cdot \frac{d j(\varphi)}{d \varphi} \cdot \frac{(\omega \cdot \tau)}{2}\right)^{2} .
$$

The attraction force, determined by magnetic behavior of car body panel metal, is described by the dependence

$$
\begin{aligned}
& P_{M}(\varphi, r)=-\frac{\mu_{0}}{2}\left(\mu_{r}-1\right) \\
& \quad \times\left(\mu_{r}\left[H_{z}^{2}(\zeta=0)-H_{z}^{2}(\zeta=d)\right]\right. \\
& \left.+\left[H_{r}^{2}(\zeta=0)-H_{r}^{2}(\zeta=d)\right]\right),
\end{aligned}
$$

where $H_{z, r}(\zeta=0), H_{z, r}(\zeta=d)\{z$ and $r\}$ are the magnetic field strength components on the edge surfaces of car body panel.

Such criteria were found for numerical estimates carrying out: $R_{1}=0,025 \mathrm{~m}, R_{2}=0,035 \mathrm{~m}, h=0,001 \mathrm{~m}, f=1150 \mathrm{~Hz}, \delta=$ $0,2, I_{m}=50 \mathrm{kA}, d=0,00075 \mathrm{~m}, \gamma=0,4 \cdot 10^{7} 1 /(\mathrm{Ohm} \cdot \mathrm{m}), \mu_{r} \approx$ 2,5. The results of calculations are presented in Figure 6.

We can draw the following conclusions after analyzing the obtained calculations results.

(1) The magnetic capabilities effect of screen and car body panel is manifested in the appearance of the powerful forces of magnetic attraction.

(2) The superposition of Ampere's attraction forces and magnetic attraction forces in the radial distributions turn off dip of the force impact to car body panel in the single turn inductor area.

(3) In general, ferromagnetic attraction in considered ISAS is more effective than a nonmagnetic metal. Inductor current with time dependence in the form of an exponentially damping sine with an amplitude of $37 \mathrm{kA}$ excites the attraction force about $(35, \ldots, 80)$. $10^{5} \mathrm{~N} / \mathrm{m}^{2}$.

(4) The evaluation of the average force values showed that the total attraction force mean value (Ampere's force plus the magnetic attraction force) during its action can come up to $110 \cdot 10^{5} \mathrm{~N} / \mathrm{m}^{2}$.

\section{Experimental Validation}

The material had the following properties: yield stress was $310 \mathrm{MPa}$; specific conductivity was $0,4 \cdot 10^{7} \mathrm{l} /(\mathrm{Ohm} \cdot \mathrm{m})$. The sheet metal screen was rigidly mounted on a surface of 


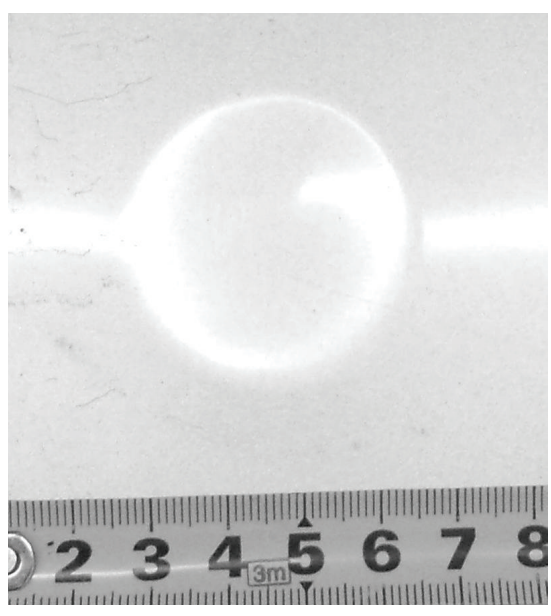

(a)

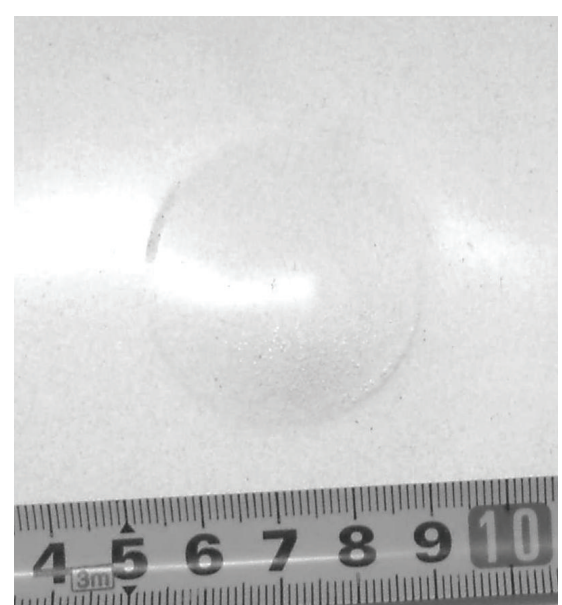

(b)

FIGURE 7: Experimental investigation with ISAS: (a) after producing the dent; (b) after removing the dent.

a massive dielectric plate preventing deformation of the screen. A single turn inductor with the inner diameter of $60 \mathrm{~mm}$ was mounted on top of the screen and was covered by an insulating plate $1 \mathrm{~mm}$ thick. The blank was made from the same $1 \mathrm{~mm}$ stainless steel sheet. The working zone of the investigated inductor system is the round opening with diameter $45 \mathrm{~mm}$ in the insulating plate on the inductor. The part of the sheet metal blank positioned against the opening in the insulating plate was expected to be deformed by the EMF attraction forces. The amplitude of the electric current running through the coil was $J_{m}=39,2 \mathrm{kA}$, and the frequency of the discharge was $f=2 \mathrm{kHz}$. The relative damping coefficient was $\delta_{0}=0,3$. After eight discharges, the sheet metal blank was attracted into the inner opening of the working zone: the dent had a diameter of $40 \mathrm{~mm}$ and a depth of $1 \mathrm{~mm}$ formed on the surface of sheet metal blank (Figure 7(a)). The repetition frequency of the discharge pulses is $\sim 10 \mathrm{~Hz}$. That is, the process of attraction took about 1 second.

Further researches were carried out similar to the previous review. After the initial bulge was produced on a flat blank using the described process of electromagnetic attraction, it was flipped over, and dent removal process was physically simulated by pulling the bulge back with the electromagnetic attraction process. The experimental sample is shown in Figure 7(b). The dent was successfully removed which confirmed the suggested concept.

It should be noted that while pilot investigating, the protective paint of the car body panels was not damaged. This fact opens up enough great opportunities and perspectives in the creation and production of new advanced equipment for repair technology.

\section{Conclusions}

The conducted theoretical analysis and experiments confirmed the proposed concepts of the inductor systems for ferromagnetic and nonferromagnetic blank materials. The mentioned inductor system can be used as a tool of external magnetic-pulse straightening of car body panels. In such a case, efficient dents removal is made from outside of a car body panel and without painting damage.

\section{Conflict of Interests}

The authors declare that there is no conflict of interests regarding the publication of this paper.

\section{References}

[1] V. Psyk, D. Risch, B. L. Kinsey, A. E. Tekkaya, and M. Kleiner, "Electromagnetic forming-a review," Journal of Materials Processing Technology, vol. 211, no. 5, pp. 787-829, 2011.

[2] Laboratory of the Electromagnetic Technologies, "Materials site," 2015, http://electromagnetic.comoj.com.

[3] Welcome to BETAG Innovation, 2014, http://www.beulentechnik.com/.

[4] D. Taylor, Paint \& Body Handbook, HP Trade, 1994.

[5] J. Haynes, The Haynes Automotive Body Repair \& Painting Manual, Haynes Manuals N. America, 1st edition, 1989.

[6] K. Faes, O. Zaitov, and W. De Waele, "Electromagnetic pulse crimping of axial form fit joints," in Proceedings of the 5th International Conference on High Speed Forming, pp. 229-242, Dortmund, Germany, April 2012.

[7] D. Risch, A. Brosius, and M. Kleiner, "Influence of the workpiece stiffness on the electromagnetic sheet metal forming process into dies," Journal of Materials Engineering and Performance, vol. 16, no. 3, pp. 327-330, 2007.

[8] D. A. Oliveira, M. J. Worswick, M. Finn, and D. Newman, "Electromagnetic forming of aluminum alloy sheet: free-form and cavity fill experiments and model," Journal of Materials Processing Technology, vol. 170, no. 1-2, pp. 350-362, 2005.

[9] H. Huh, S. Jeong, G. W. Bahng, K. S. Chae, and C. G. Kim, "Standard uncertainty evaluation for dynamic tensile properties of auto-body steel-sheets," Experimental Mechanics, vol. 54, no. 6, pp. 943-956, 2014. 
[10] X. Liu, L. Huang, and J. Li, "An experiment and simulation study of the rebound effect in electromagnetic forming process," in Proceedings of the 6th International Conference on High Speed Forming, pp. 131-140, Dortmund, Germany, May 2014.

[11] Y. V. Batygin, S. F. Golovashchenko, and A. V. Gnatov, "Pulsed electromagnetic attraction of sheet metals-fundamentals and perspective applications," Journal of Materials Processing Technology, vol. 213, no. 3, pp. 444-452, 2013. 

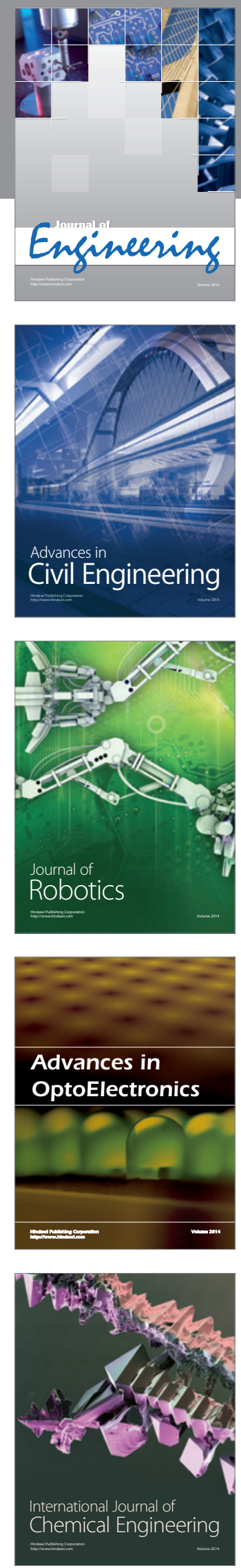

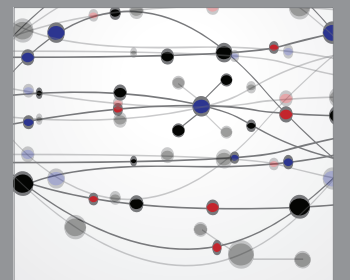

The Scientific World Journal
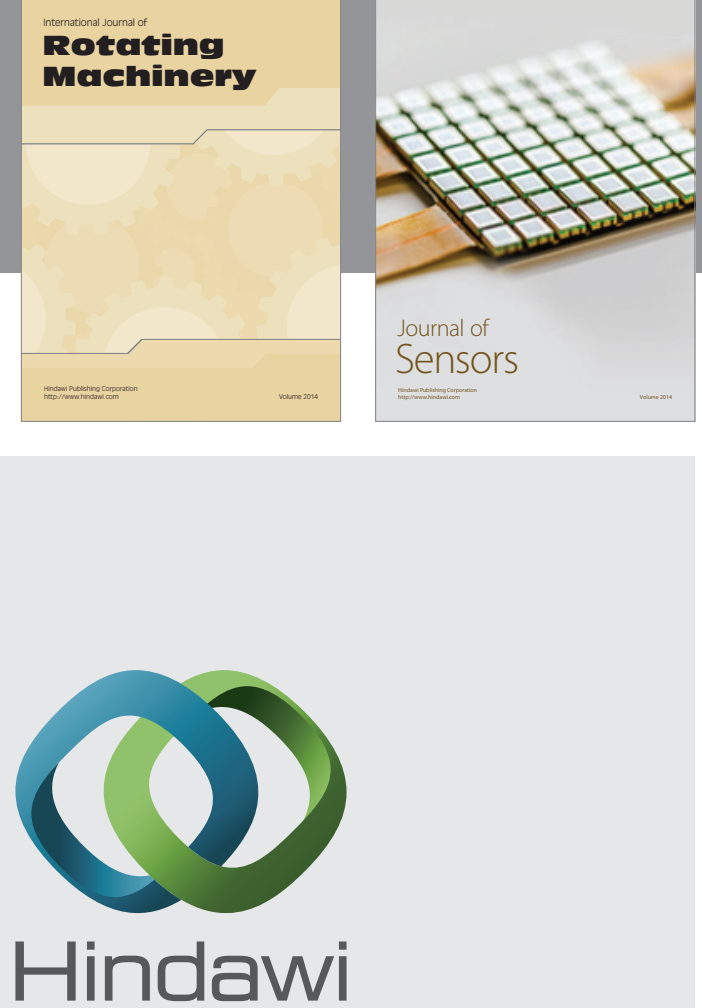

Submit your manuscripts at http://www.hindawi.com
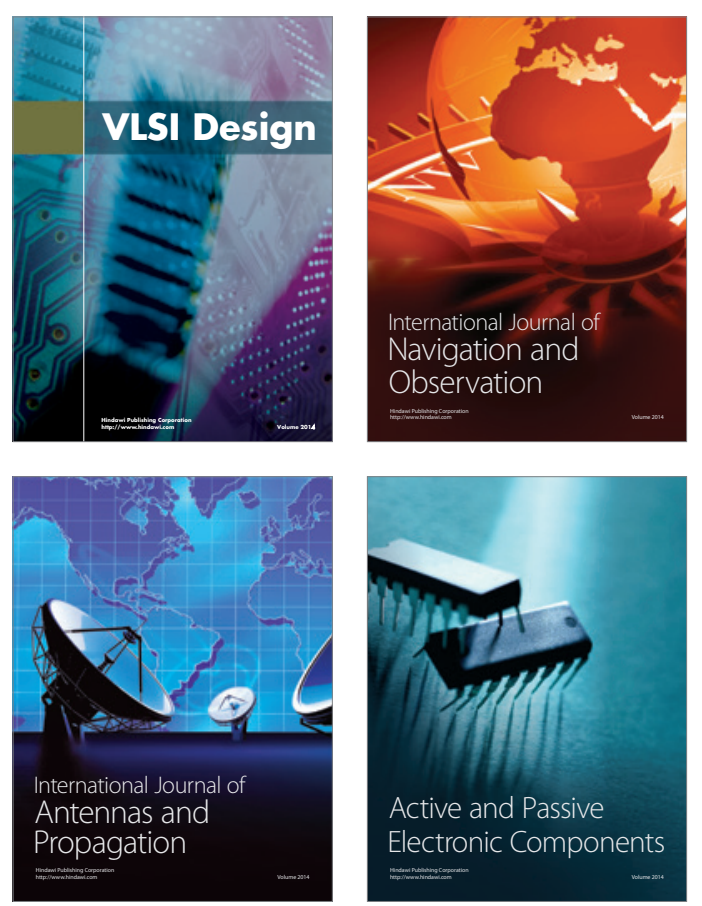
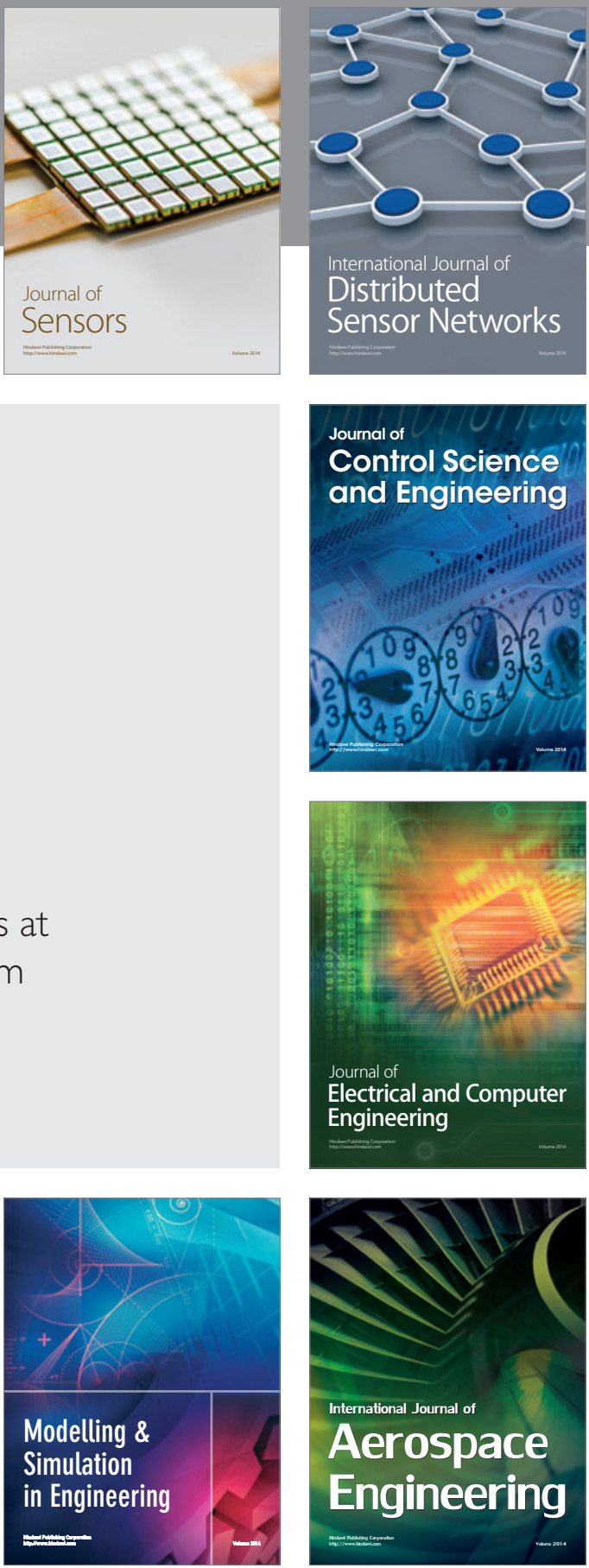

Journal of

Control Science

and Engineering
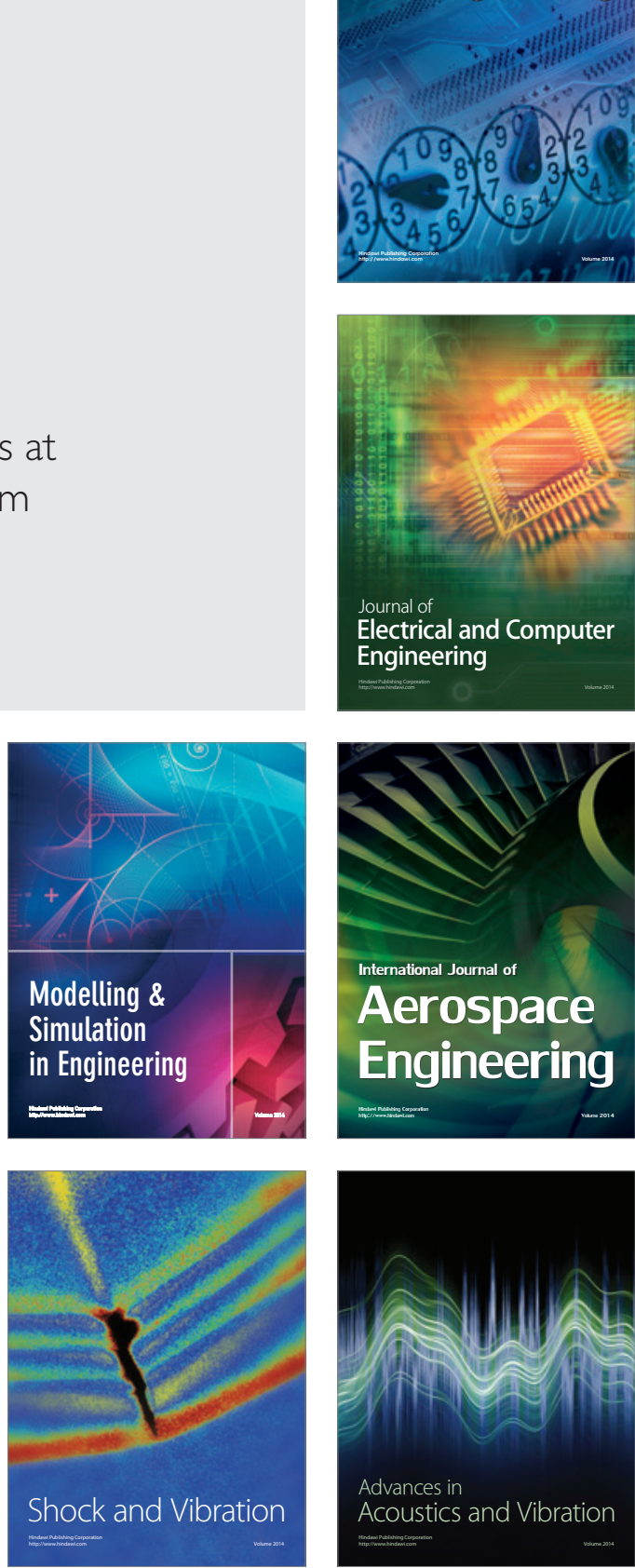